\title{
As Fake News sob a perspectiva dos estudantes dos cursos de gra- duação e técnico em Biblioteconomia de Porto Alegre (RS): um es- tudo de caso
}

\author{
Fake News from the perspective of undergraduate and technical students in Library Science \\ in Porto Alegre (RS): a case study
}

\author{
Bruno Fortes Luce \\ Mestre em Informática na Educação \\ Instituto Federal de Educação, Ciência e Tecnologia do Rio Grande do Sul \\ brunofluce@gmail.com \\ Laura Valladares Soares \\ Douturanda em Educação em Ciências, Química da Vida e Saúde \\ Universidade Federal do Rio Grande do Sul \\ laurinhavalladaresbr@gmail.com \\ Filipe Xerxeneski da Silveira \\ Douturando em Educação em Ciências, Química da Vida e Saúde \\ Universidade Federal do Rio Grande do Sul \\ filipe.silveira@poa.ifrs.edu.br \\ Lizandra Brasil Estabel \\ Doutora em Informática na Educação \\ Instituto Federal de Educação, Ciência e Tecnologia do Rio Grande do Sul \\ lizandra.estabel@poa.ifrs.edu.br
}

\begin{abstract}
Resumo
Este estudo apresenta a relação dos alunos do curso técnico em Biblioteconomia do Instituto Federal do Rio Grande do Sul (IFRS)- Campus Porto Alegre e do curso de graduação em Biblioteconomia da Universidade Federal do Rio Grande do Sul (UFRGS) com as fontes de informação e fake news. Para a realização da pesquisa, de caráter exploratório, utilizou-se como instrumento para a coleta dos dados um questionário que foi aplicado aos participantes, posteriormente analisados de forma qualitativa e quantitativa. Foram entrevistados 44 sujeitos, oriundos dos cursos técnico e graduação em Biblioteconomia. Como resultado da pesquisa, destaca-se a importância de abordar a temática fake news e enfocar a alfabetização midiática e informacional (AMI), tanto em ações de extensão como cursos e palestras, quanto na inclusão dos currículos dos cursos, a fim de preparar os futuros técnicos e bibliotecários para lidar com o fenômeno da desinformação, e atuarem na orientação do acesso e uso de mídias, e produção da informação pela sociedade.
\end{abstract}

\section{Palavras-chave}

Fake News. Biblioteconomia - Curso Técnico. Biblioteconomia - Graduação. Desinformação. PósVerdade.

\section{Abstract}

This study presents the relationship of students from the technical course in Library Science at the Federal Institute of Rio Grande do Sul (IFRS) - Porto Alegre Campus and the undergraduate course in Library Science at the Federal University of Rio Grande do Sul (UFRGS) with the sources of information 
and fake news. To carry out the research, of an exploratory nature, a questionnaire was used as an instrument for data collection, which was applied to the participants, subsequently analyzed qualitatively and quantitatively. 44 subjects were interviewed, from the technical and undergraduate courses in Library Science. As a result of the research, the importance of addressing the fake news theme and focusing on media and information literacy (AMI) is highlighted, both in extension actions such as courses and lectures, as well as in the inclusion of course curricula, in order to prepare the future technicians and librarians to deal with the phenomenon of misinformation, and act in guiding the access and use of media, and production of information by society.

\section{Keywords}

Fake News. Librarianship - Technical Course. Librarianship Graduate. Disinformation. Post-Truth.

\section{INTRODUÇÃO}

As Tecnologias de Comunicação e de Informação (TIC) auxiliaram a expansão de conteúdos informacionais transcendendo barreiras físicas, com um alcance maior e um número variado de receptores. Segundo Dias e Pires (2005, p.60): “A informação é um fenômeno de comunicação presente em todas as áreas do conhecimento e tem valor em função do contexto, do interesse do receptor, do seu grau de competência e domínio sobre aquele assunto." Capurro e Hjorland (2007, p.155) vão além e traçam dois contextos para informação: "[...] o ato de moldar a mente e o ato de comunicar conhecimento." No que concerne às fontes de informação Blattmann (2010, online) sugere que: "[...] existem fontes e recursos informacionais orais, impressos, digitais e multimídia. Cada qual apresenta sua função, diferencia-se pelo seu conteúdo e, principalmente, pelo público-alvo a qual é direcionado."

Com advento da internet, a produção de fontes de informação em formato digital, facilitou processo de compartilhamento. Guimarães (2008, p. 173) corrobora com essa afirmação: "[...] além de reunir em uma única mídia os vários formatos que a precederam, a internet contém as ferramentas necessárias para encontrar as informações disponíveis em si mesma."

A facilidade de propagação, deu-se por meio da popularização das redes sociais, que de acordo com Aguiar (2012), não podem se limitar somente a mediação de dispositivos eletrônicos, visto que a interação entre pessoas é o seu principal foco, tanto virtual como presencial. Aguiar (2012), exemplifica outras características para definir uma rede social dentro da Web:

a) Ferramentas síncronas (chat) e assíncronas (fóruns, grupos, eventos, notas, entre outros); b) Interface customizável; c) Recursos como vídeos, fotos e imagens, e links para outras interfaces; d) Possibilitam uma comunicação mais direta e informal, com trocas de informações entre os próprios usuários; e) Oportunidade de criar comunidades de interesse e perfis; f) Divulgação e o compartilhamento de informações, produtos e serviços; g) Exposição das conexões sociais de um indivíduo a outros de uma determinada comunidade; h) Participação e a colaboração do público nos processos e produtos. (AGUIAR, 2012, p.20).

Nesse espaço de troca informacional outro importante fator que tem espaço é o anonimato entre atores através de perfis. Para Recuero (2011) e Ciribeli e Paiva (2011) o anonimato permite uma maior liberdade, podendo-se expor seus pensamentos, mas resguardando sua identidade pessoal.

A natureza da informação em meios eletrônicos, apontada como volátil por Mostafa e Terra (1998), reinventou o papel do bibliotecário, como apontam os autores. Com isso, atribuições como gerenciamento de bases de dados e repositório digitais, se tornam rotinas no 
dia a dia do bibliotecário. Com a consolidação das redes sociais e os efeitos causados pela desinformação, o profissional da informação ganha mais um papel de destaque relacionado aos ambientes de propagação informacional digital: como mediador de informações checadas e fidedignas, mas também aplicando a alfabetização informacional visando a contenção da propagação de fake news, conforme relatório da UNESCO (2016).

Vislumbrando esse cenário de compartilhamento de fake news e uso das TIC, esse estudo tem como objetivo principal identificar as percepções e entendimentos acerca do tema Fake News pelos alunos do Curso Técnico em Biblioteconomia do Instituto Federal do Rio Grande do Sul (IFRS), Campus Porto Alegre, e pelos alunos do Curso de Graduação em Biblioteconomia da Universidade Federal do Rio Grande do Sul (UFRGS). Para o desenvolvimento da pesquisa, de caráter exploratório, utilizou-se um questionário de perguntas fechadas para cada participantes, optando-se, desta forma, por uma abordagem qualitativa e quantitativa na análise dos dados.

\section{REVISÃO DA LITERATURA}

O termo fake news ainda gera debate entre os pesquisadores da área, sendo algo que transcende sua tradução literal do inglês para o português (Fake News = Notícias Falsas). De acordo com Ireton e Posetti (20018, p.15) "Fake News é hoje muito mais do que um rótulo para informações falsas e enganosas, disfarçadas e divulgadas como notícias. Tornou-se um termo emocional, armado para debilitar e depreciar o jornalismo."

Autores como Ribeiro e Ortellado (2018), também afirmam que a definição ainda não encontra um consenso entre a sociedade acadêmica, mas acreditam que os acontecimentos de dois eventos de proporções globais foram responsáveis por uma maior visibilidade para as Fake News: as Eleições Americanas de 2016 e a saída do Reino Unido da União Europeia (BREXIT), no mesmo ano.

No ano de 2016, outro termo ainda não conhecido e também relacionado aos eventos mencionados anteriormente, ganhou destaque: a pós-verdade. A pós-verdade foi eleita pelo dicionário de OXFORD em 2016 como o termo do ano, tendo como definição um adjetivo onde as emoções têm maior relevância que fatos (2016, online). Autores como Dunker (2017) e D’Ancona (2017) também corroboram com essa definição, exemplificando essas ações. Dunker (2017) faz uma analogia com o filme Matrix, onde o personagem Cypher prefere aceitar viver em um ambiente não real do que habitar o mundo real. D’Ancona (2017) por sua vez, utiliza as eleições americanas de 2016, na qual Donald Trump foi eleito, e aponta que os eleitores do candidato republicano conheciam seu perfil impetuoso e suas falhas de caráter e, ainda assim, optaram por votar nele. Além disso, os autores também reforçam a importância da diferenciação entre pós-verdade e fake news, pontuando que apesar de serem termos que se relacionam, são distintos. Enquanto as fake news por si só são a materialização do conteúdo enganoso, a pós-verdade é o sentimento do receptor em preferir aceitar a mentira do que os fatos reais (DUNKER, 2017; D'ANCONA, 2017; IRETON, POSETTI, 2018).

As fake news encontram um ambiente favorável para se propagarem com facilidade em uma sociedade imersa na pós-verdade. E além desse fator, a estruturação para disseminação também ganha ajuda com a evolução de tecnologias, tais como os bots. O termo bots vem da redução da palavra em inglês robot (robôs), com isso configurando um robô que atua dentro das redes sociais (Garrett, 2018, on-line). Segundo Wang, Angarita e Renna (2018, p. 3, 
tradução nossa): "Os bots sociais são agentes de software que coabitam com humanos no ecossistema de mídia social." 1

Os autores também exemplificam a atuação desses robôs, que conseguem socializar nas redes sociais por conta de utilizarem uma linguagem natural, e com isso compartilham mais mensagens que pessoas reais, conseguindo assim disseminar um número maior de fake news (WANG; ANGARITA; RENNA, 2018). Além da utilização de bots para impulsionar e assim compartilhar uma quantidade maior de conteúdo duvidoso, outro mecanismo que é utilizado para ludibriar os receptores é conhecido com deep-fake-news, ou apenas deep-fake.

A Deep-Fake é considerada por alguns autores como a evolução das fake news que conhecemos (CHESNEY; CITRON, 2018; DACK, 2019). Para Chesney e Citron (2018, on-line, tradução nossa) as Deep Fake são: “[...] algoritmos de aprendizado de máquina combinados com software de mapeamento facial que permitem a fabricação barata e fácil de conteúdo que sequestra a identidade - voz, rosto, corpo." 2 Dack (2019, on-line, tradução nossa) simplifica mostrando que a Deep Fake: "[...] áudio ou vídeo falso hiper-realista criado usando aprendizado de máquina que é quase impossível de detectar" ${ }^{3}$ podendo-se assim, atribuir falas e imagens a situações que nunca aconteceram realmente.

Com o intuito de conter a propagação dessas falsas notícias, medidas estão sendo tomadas em todas as esferas sociais. Uma delas é o trabalho de agências checadoras de informação, conhecido como fact-checking. Apontado pela UNESCO (2019) em seu Manual para Educação e Treinamento em Jornalismo, como uma das soluções para conter o avanço de fake news, o Fact Checking é uma prática fundamental para o jornalismo e para quem trabalha com informação nos dias atuais.

Em sua tradução literal do inglês para o português, o Fact-Checking nada mais é do que a checagem dos fatos. Fonseca (2017) exemplifica essa checagem como "[...] um confrontamento de histórias com dados, pesquisas e registros". Desta forma, ao analisar as informações com fontes fidedignas, o objetivo é de certificar-se sobre a veracidade dos fatos. Além do trabalho de checagem, a UNESCO também aponta maneiras através da educação para mitigar esse problema, e uma das formas encontradas é através da instrução e conscientização da sociedade, o que se dá por meio da Alfabetização Midiática Informacional (AMI).

A AMI é um conceito composto que unifica os termos Alfabetização Midiática e Alfabetização Informacional. De acordo com a definição da UNESCO $(2016$, p. 7) a AMI é "[...] uma base para aumentar o acesso à informação e ao conhecimento, intensificar a liberdade de expressão e melhorar a qualidade da educação." Além disso, ela é responsável por:

Descrever as habilidades e atitudes necessárias para valorizar nas sociedades as funções das mídias e de outros provedores de informação, incluindo aqueles na internet, bem como para encontrar, avaliar e produzir informações e conteúdos midiáticos; em outras palavras, apresenta as competências fundamentais para que as pessoas participem de maneira eficaz de todos os aspectos do desenvolvimento (GRIZZLE, 2016, p. 7).

\footnotetext{
${ }^{1}$ Citação original de Wang, Angarita e Renna (2018, p. 3): "Social bots are software agents that cohabit with humans in the so-cial media ecosystem."

${ }^{2}$ Citação original de Chesney e Citron (2018, on-line): “Machine-learning algorithms (often neural networks) combined with facial-mapping software enable the cheap and easy fabrication of content that hijacks one's identity-voice, face, body."

${ }^{3}$ Citação original de Dack (2019, on-line): "hyper realistic, fake audio or video created using machine learning that is nearly impossible to detect."
} 
A AMI tem como objetivo empoderar as pessoas, desenvolvendo habilidades necessárias para a competência de compreender o papel e as funções que a mídia tem na sociedade. Ela tem como propósito permitir aos alunos:

Uma aprendizagem mais autônoma para que possam utilizar as mídias e as comunicações tanto como ferramentas, quanto como uma maneira de articular processos de desenvolvimento e mudança social (GRIZZLE, 2016, p. 8).

As políticas e estratégias da AMI devem ter como base um conceito, que seja capaz de harmonizar e incluir diferentes tipos de habilidades para o desenvolvimento de competências, que na era digital podem ser identificadas como: alfabetização no acesso a notícias, alfabetização televisiva, alfabetização cinematográfica, alfabetização computacional, alfabetização no uso da internet, alfabetização digital e alfabetização em mídias sociais (GRIZZLE, 2016, p. 13).

No ano de 2017, a pedido do Conselho da Europa (COE), foi elaborado por Wardle e Darakhshan (2017) um relatório no qual consta que a propagação de fake news é um problema que engloba diversas esferas. Desta maneira, após reconhecer o problema, a implementação da AMI foi vista como uma das maneiras de mitigar seu avanço. Para tal, os autores sugerem que haja uma parceria entre professor e bibliotecário, bem como uma atuação educativa do próprio bibliotecário. No entanto, para que isso aconteça é fundamental que esse profissional também seja capacitado para lidar com essas novas questões impostas pelo avanço das tecnologias.

\section{CONTEXTUALIZAÇÃO HISTÓRICA DOS CURSOS TÉCNICO E GRADUAÇÃO EM BIBLIOTECO- NOMIA EM PORTO ALEGRE}

Através do Decreto no 8.835, de 11 de julho de 1911, oficializou-se a criação do primeiro Curso de Biblioteconomia no Brasil, embora a data do Decreto seja de 1911, somente quatro anos depois da sua publicação que as aulas começaram oficialmente (CASTRO, 2000; ALMEIDA, BAPTISTA, 2013). O curso situado na cidade do Rio de Janeiro teve como berço a Biblioteca Nacional, e sua base curricular de cunho francês, que englobava apenas três disciplinas: Bibliografia, Paleografia e Diplomática, Iconografia e Numismática, (MULLER, 1985). O segundo curso em território nacional foi na cidade de São Paulo, em 1929, no Mackenzie College com a tutela da bibliotecária americana Dorothy Muriel Gedds Gropp. Com a implementação do curso em São Paulo, e influência norte-americana, criou-se uma rivalidade entre duas influências educacionais distintas: a francesa e a estadunidense (MULLER, 1985).

As duas escolas do sudeste do Brasil deram origem aos próximos cursos que iriam se espalhar para as outras regiões do país. Na década de 40, mais-quatro cursos surgiram em outras capitais brasileiras, por meio da atuação de ex-alunos dos cursos de São Paulo e Rio de Janeiro:

Os cursos de Biblioteconomia de São Paulo e do Rio de Janeiro eram os únicos do país, e para eles vieram alunos dos estados, amparados por um sistema de bolsas de estudo. De volta aos seus estados de origem, os bolsistas lá organizaram cursos ou escolas. Surgiram, assim, cursos em Salvador, Porto Alegre, Recife e Manaus (MULLER, 1985, p.5. grifo nosso).

No ano de 1947, foi fundado o primeiro Curso de Biblioteconomia na região Sul do Brasil, na cidade de Porto Alegre. Designada para construção e estruturação do novo curso, Ângela da Costa Franco Jobim, que atuava como bibliotecária da Secretária da Agricultura do Rio Grande do Sul, teve sua formação constituída na escola de São Paulo, e incorporou este 
currículo para a formação do curso (SANTOS; SILVEIRA, 2000). Atualmente o Curso de Biblioteconomia é ofertado pela Faculdade de Biblioteconomia e Comunicação (FABICO) da UFRGS.

O curso de bacharelado tem carga horária de 2.850 horas, dividido em um total de 190 créditos em oito semestres, com a função de preparar o estudante para:

[...] planejar, implantar e implementar unidades, sistemas e serviços de informação e documentação, bancos e bases de dados; promover o acesso às fontes de informação sob diferentes suportes; difundir a importância da leitura e os benefícios do uso da informação; acolher e orientar o usuário para a leitura, a pesquisa e a produção textual (UFRGS, 2020, on-line).

O bacharelado tem como principal objetivo preparar os alunos para atuação em diferentes espaços informacionais, não se limitando apenas a tipologia das bibliotecas: escolares, públicas, universitárias ou especializadas, tornando-os aptos ao trabalho tanto no setor público quanto no setor privado. Com o intuito de capacitar profissionais para atuarem junto aos bibliotecários, tornou-se necessária a criação de um curso que profissionalizasse as pessoas de maneira formal.

O Curso Técnico em Biblioteconomia surgiu por uma demanda de profissionais para auxiliar o bibliotecário em espaços informacionais. Conforme Estabel e Moro (2015, p.1) “[...] o curso foi criado para atender a necessidade de formação profissional, em nível pós-médio (técnico), capacitado e habilitado para atuar como assistente junto aos bibliotecários, nas diferentes tipologias de bibliotecas."

O Curso Técnico em Biblioteconomia foi criado em 2004, através de parceria entre a Escola Técnica da UFRGS e o Curso de Biblioteconomia da UFRGS. A partir de 2009, através da Lei no 11.892/2008, que criou os Institutos Federais, ocorreu a desvinculação da Escola Técnica da UFRGS e passou a pertencer ao IFRS. O Curso que antes era situado em um prédio anexo a FABICO, passou a funcionar no centro de Porto Alegre (ESTABEL; MORO, 2015).

O curso Técnico, assim como o curso de Graduação, é presencial e diurno, tendo como carga horária 1.312 horas e duração de três semestres. De acordo com o projeto pedagógico do curso:

[...] caracteriza-se pelo conjunto de conhecimentos teóricos e técnicos indispensáveis para armazenar, recuperar e disseminar informações em qualquer tipo de veículo ou formato, para pessoas ou grupos, de maneira ágil e dinâmica. (ESTABEL, FLACH, SILVA, 2010, p. 5).

Tendo em vista os objetivos principais dos dois cursos, é possível notar que os alunos são preparados para atuar em bibliotecas e no mundo do trabalho, em níveis hierárquicos diferentes mas de forma colaborativa, promovendo o acesso, o uso e a produção da informação para a sociedade e o exercício da cidadania.

\section{PROCEDIMENTOS METODOLÓGICOS}

A pesquisa realizada tem caráter exploratório, com abordagem qualitativa e quantitativa, e visa identificar as percepções e entendimentos acerca do tema Fake News pelos alunos do ensino técnico e superior em Biblioteconomia. Para tal, foi aplicado um questionário com perguntas fechadas, entregue juntamente com um termo de consentimento livre e esclarecido (TCLE), para cada um dos participantes. 
A seleção dos sujeitos e coletas de dados ocorreram durante dois momentos distintos: na semana Acadêmica do Curso de Biblioteconomia da UFRGS (16/10/2018) e no III Encontro Estadual de Leitura Inclusiva (13/11/2018), evento promovido pelo Grupo Interinstitucional de Pesquisa LEIA: leitura, informação e acessibilidade (da UFRGS e do IFRS), em parceria com a Fundação Dorina Nowill para Cegos (SP), realizados na FABICO.

Esses eventos contaram com palestras dos pesquisadores que abordaram o tema das fake news no contexto da pesquisa científica. Após o término das palestras os questionários foram entregues aos participantes, não sendo obrigatório o seu preenchimento.

Para o estudo, foram selecionados através dos participantes das palestras, estudantes matriculados nos cursos de Graduação em Biblioteconomia da UFRGS e no curso Técnico em Biblioteconomia do IFRS, sendo assim, excluídos os outros participantes dos eventos que não se enquadravam nesse critério. Devido a questão geográfica, todos os participantes estudavam na cidade de Porto Alegre, perfazendo um total de 44 participantes, sendo 12 alunos do Curso Técnico e 32 alunos do Curso de Graduação.

A diferença entre o número de sujeitos pode ser explicada pelos seguintes fatores: as palestras ocorreram durante a realização dos eventos na FABICO, o que pode ter facilitado a participação dos integrantes do Curso de Graduação em Biblioteconomia, visto que era necessário o deslocamento dos alunos do Curso Técnico. Outro fator é a realização de palestra na semana acadêmica da graduação e, ainda, o número de vagas para o curso de graduação que é de 75 vagas $^{4}$ anuais divididas em dois semestres, enquanto que no curso Técnico são 24 vagas por semestre.

Outro ponto de destaque foi a diferença de idade entre os participantes dos cursos. Enquanto que no Curso Técnico a média de idade dos alunos é de 39 anos, sendo que a aluna mais velha tem 63, no Curso de Graduação a média de idade é de 24 anos, tendo uma participante bem mais jovem, com 17 anos. Nas subseções a seguir, serão apresentados os resultados e a discussão em torno dos dados levantados.

\section{APRESENTAÇÃO E ANÁLISE DOS DADOS}

Os dados a seguir, serão apresentados de maneira linear, conforme a ordem das perguntas do questionário, criando assim uma narrativa entre o leitor e o texto, com o intuito de facilitar a compreensão do método utilizado pelos pesquisadores, em anexo (Anexo A) se encontra o questionário aplicado na íntegra para consulta. As três primeiras perguntas foram feitas para conhecer a relação dos entrevistados com as fakes news de maneira mais direta.

Através da primeira pergunta foi possível notar que os alunos do Curso Técnico em Biblioteconomia se mostraram mais confiantes em relação a identificação de fake news, com nove sujeitos assinalando que teriam habilidades para reconhecer e apenas três sujeitos marcando que não. Com relação aos estudantes do Curso de Graduação, 19 sinalizaram que sabiam reconhecer as fake news, enquanto que 13 assinalaram que não saberiam. Proporcionalmente, os alunos do Curso de Biblioteconomia se consideraram com menor habilidade de identificar uma 'fake news', enquanto $25 \%$ dos alunos do Curso Técnico disseram que não conseguiriam reconhecer uma 'fake news', no Curso de Graduação este percentual sobe para $40 \%$.

\footnotetext{
${ }^{4}$ Os números foram retirados dos sites das instituições:

FABICO: http://www.ufrgs.br/fabico/graduacao/biblioteconomia/ingresso-e-vagas

IFRS: https://ingresso.ifrs.edu.br/2020/cursos/tecnico-em-biblioteconomia/
} 
Sobre o compartilhamento de fake news nas redes sociais, sete participantes do Curso Técnico falaram que não compartilharam uma 'fake news' nas redes sociais e depois descobriram que era uma notícia falsa, enquanto que dos alunos do Curso de Graduação, 14 disseram que nunca fizeram o mesmo. Ainda, ao analisar os dados da pesquisa, foi possível perceber que de um total de 28 sujeitos (de ambos os cursos) que assinalaram reconhecer uma 'fake news', cinco destes mesmo sujeitos também assinalaram já terem compartilhado uma destas notícias falsas. Todos os participantes que responderam que não sabiam reconhecer uma 'fake news' também marcaram que nunca compartilharam uma fake news, despertando assim a dúvida: como é possível saber que nunca compartilharam uma 'fake news' já que afirmaram que não saberiam reconhecer?

A terceira pergunta correspondia na identificação de quem é o responsável na propagação do material tendencioso, e para isso foram apresentadas três alternativas: A responsabilidade é de quem compartilha; de quem produziu a notícia; ou de ambos? Através do Gráfico 1 , pode-se perceber que a maioria dos sujeitos considerou que as duas ações são responsáveis pela proliferação de fake news:

Gráfico 1 - A responsabilidade pela propagação de fake news:

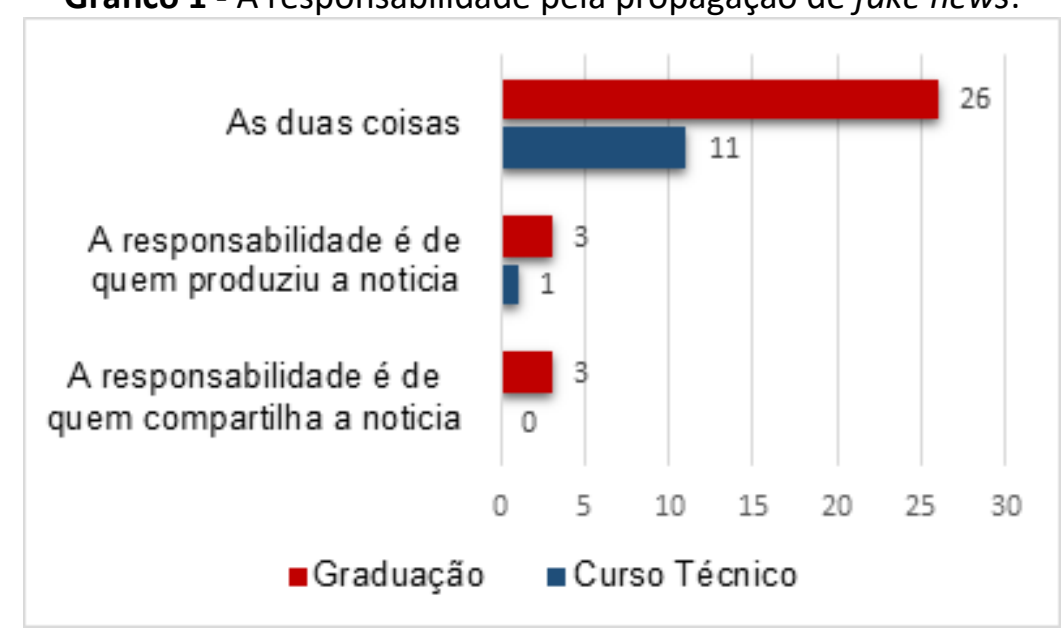

Fonte: Elaborado pelos autores (2020).

Ao traçarmos um paralelo com as duas primeiras perguntas, foi possível perceber que dois estudantes que assinalaram sobre "a culpa é de quem compartilha", também afirmaram já terem compartilhado uma 'fake news'. Na mesma comparação, três sujeitos marcaram que a culpa é de quem produz, e 18 participantes marcaram que a culpa é de ambos. Desta forma, ao estabelecer uma relação entre os estudantes que afirmaram não compartilhar, um dos sujeitos indicou que a culpa é de quem compartilha, enquanto que os demais sujeitos (18) apontaram que a culpa é de ambos.

As perguntas de número quatro, cinco e seis foram feitas para verificar o comportamento informacional em relação ao uso através do suporte, fontes e seus compartilhamentos. O Gráfico 2, ilustra a utilização de meios de comunicação tradicionais (rádio, televisão, jornais, revistas e site de notícias) para busca de informações, sendo o número um quem utiliza sempre e o número cinco quem não utiliza:

Gráfico 2 - Meios de Comunicação 


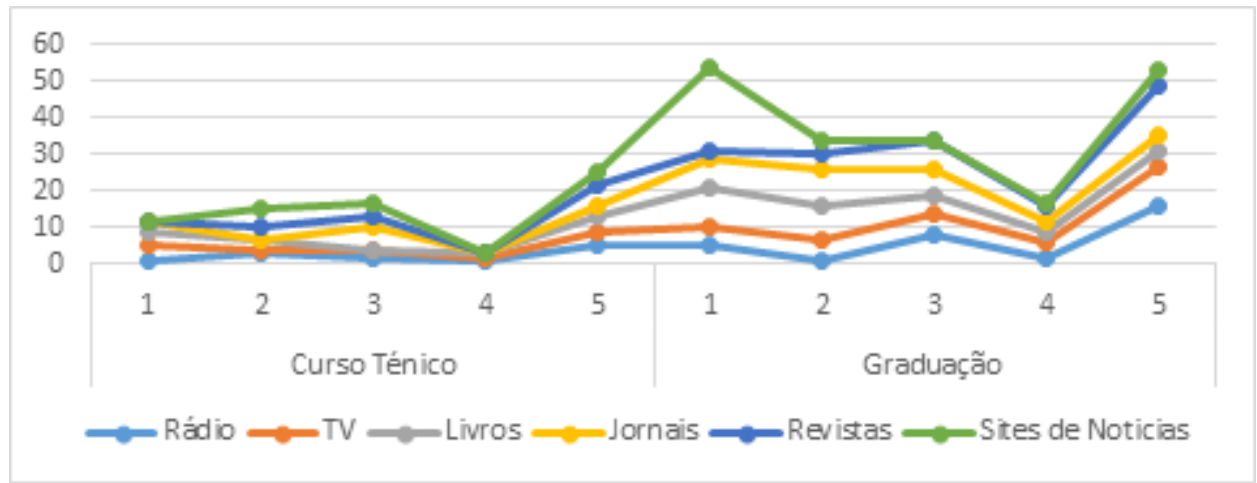

Fonte: Elaborado pelos autores (2020).

O Gráfico 2 revela que existe uma concentração principalmente nas respostas de 1 a 2 , aferindo que os participantes utilizam os meios de comunicação a fim de recuperar informação. Os formatos de rádio e revistas mostraram baixa adesão entre os entrevistados, enquanto que sites de notícias apresentaram uma adesão maior em relação aos alunos da graduação, com 23 estudantes marcando como mais utilizado. O Gráfico 3 ilustra a mesma relação de busca por informação, mas utilizando as redes sociais (Facebook, Instagram, Twitter, Whatsapp, Blogs, Youtube, Podcast).

Gráfico 3 - Relação Informação e Redes Sociais

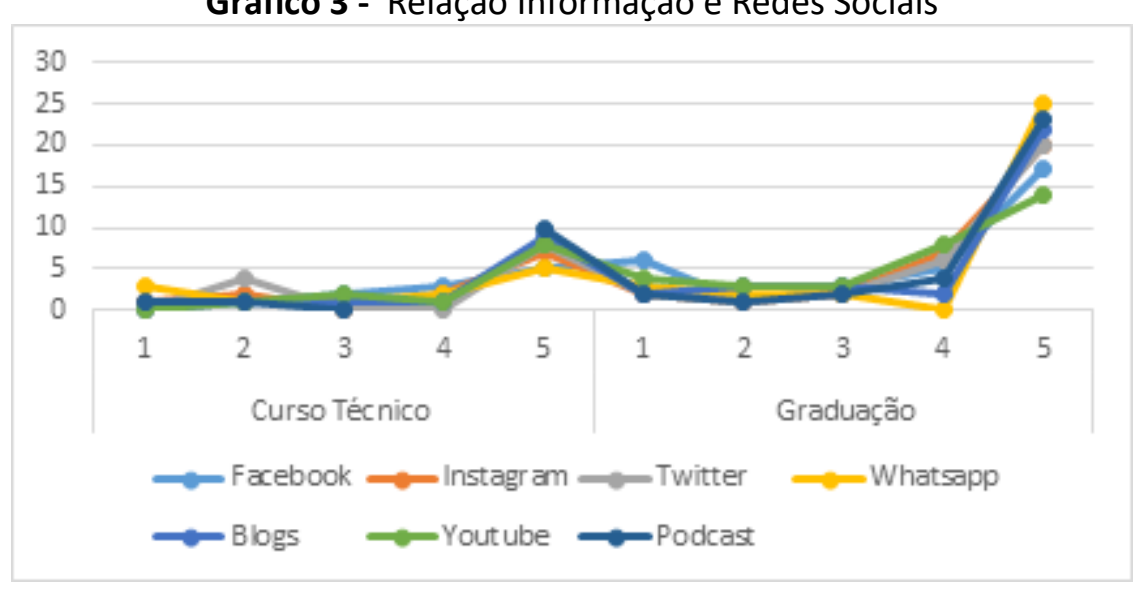

Fonte: Elaborado pelos autores (2020).

A utilização de redes sociais para busca de informação se mostrou baixa entre os participantes dos dois cursos, tendo a maioria das respostas se concentrado como menos utilizado. Em relação ao ambiente digital, também foi perguntado: "Qual o espaço informacional você mais utiliza para compartilhar conteúdos?" Para essa pergunta foram elencadas as redes sociais apresentadas no Gráfico 3, com o acréscimo de sites de notícias, sendo usado o mesmo critério de um para utilizar muito e cinco para não utilizar.

Gráfico 4 - Relação Informação, Redes Sociais e Sites de Notícias 


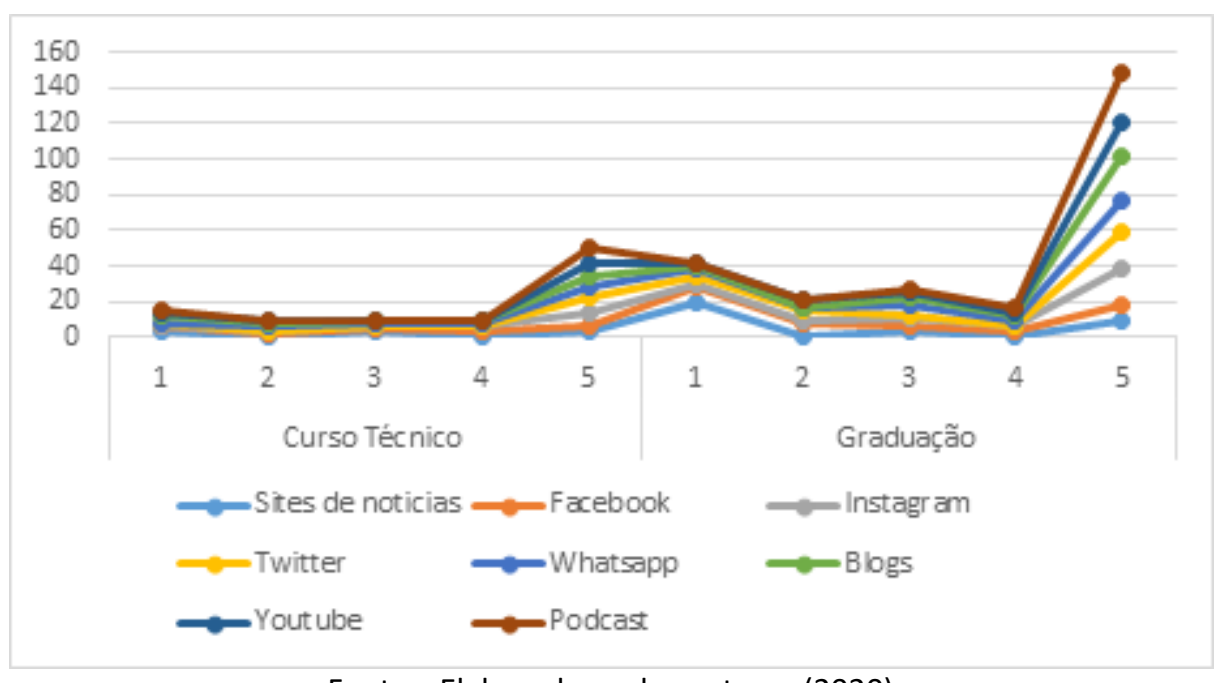

Fontes: Elaborados pelos autores (2020)

Os dados do terceiro gráfico se assemelham com o segundo, mostrando uma baixa interação nas redes sociais em relação a busca de informação. Sites de notícias aparecem como os mais compartilhados entre os sujeitos da graduação, enquanto alunos do técnico colocam Sites de notícias e Blogs como os mais utilizados. Para maioria dos participantes da pesquisa Podcast é o menos utilizado para compartilhamento, com 28 participantes da graduação e 10 participantes do Curso Técnico marcando essa alternativa. Dois participantes que disseram utilizar Podcast como fonte de informação, também marcaram que não compartilham Podcast. Através dos três gráficos apresentados anteriormente, foi possível notar que os veículos de comunicação ainda são preferência para recuperar informação pelos estudantes, superando o uso das redes sociais para esta finalidade.

A sexta pergunta, assim como a terceira, foi feita para compreender como os sujeitos da pesquisa se relacionam ao compartilhar a informação. Nenhum dos sujeitos marcou alternativa que compartilhava sem checar as fontes. Entre os alunos do Curso Técnico, sete assinalaram que nunca compartilham sem checar a fonte, desses sete, cinco marcaram na questão de número dois ${ }^{5}$ que já compartilharam notícias falsas nas redes sociais e descobriram depois. Já em relação aos alunos do Curso de Graduação, 21 assinalaram que sempre verificam a fonte, e onze participantes destes 21 , afirmaram que já compartilharam fake news em redes sociais. Ao estabelecer uma relação entre as questões, é possível perceber uma contradição nas respostas dos participantes.

A última pergunta foi realizada com o intuito de ver se o grupo reconhecia os termos apresentados. Para isso foram selecionados seis termos relacionados às fake news, mas não sinônimos da expressão. Foram eles: Fact-Checking, Bots, Fake News Científica, Pós-Verdade e Media and Information Literacy (Alfabetização Midiática Informacional). Quatro alunas afirmaram desconhecer todos os termos (duas do Curso Técnico e duas da Graduação), e somente um sujeito da pesquisa afirmou conhecer todos os termos (estudante do Curso de Técnico em Biblioteconomia). Abaixo, o Gráfico 5 apresenta os dados levantados através da última pergunta do questionário:

Gráfico 5 - Conhecimentos dos termos

${ }^{5}$ Questão de $n^{\circ} 2$ : 'Você já compartilhou algo nas redes sociais e depois descobriu que o conteúdo era falso?' 


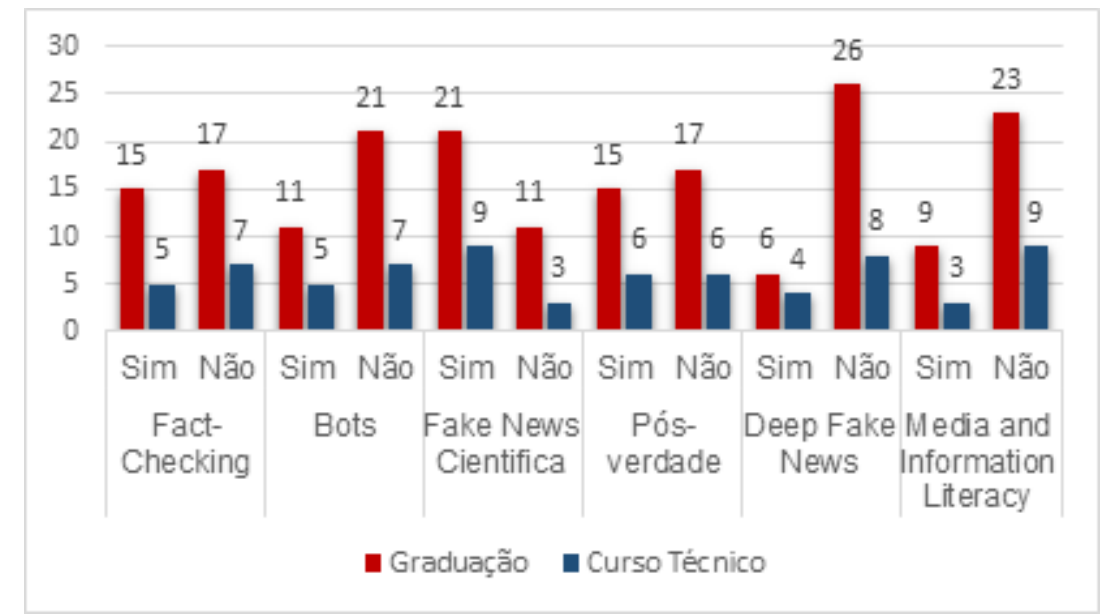

Fonte: Elaborado pelos autores (2020).

Proporcionalmente os alunos do Curso Técnico apresentaram conhecer mais os termos fornecidos do que os alunos do Curso de Graduação. Além disso, os alunos do Curso Técnico também mostraram resultados superiores em relação aos alunos do Curso de Graduação em quatro termos: Bots (Graduação 34\% e Técnico 41\%), Pós-Verdade (Graduação 48\% e Técnico 50\%), Deep-Fake News (Graduação 18\% e Técnico 33\%) e, ainda assim, ficaram abaixo dos $50 \%$. O termo que apresentou um resultado acima dos 50\% entre os participantes foi Fake News Científica. Neste caso, $65 \%$ dos alunos do Curso de Graduação afirmaram que conhecem e 75\% dos alunos do Curso Técnico.

Após a realização da análise dos dados ficou evidente a necessidade de uma pesquisa mais aprofundada em relação ao assunto abordado neste estudo, pois apesar dos alunos do Ensino Superior, ao longo de sua graduação, realizarem um maior número de discussões de cunho epistemológico, os alunos do Curso Técnico foram os que apresentaram ter maior conhecimento acerca dos termos apresentados na pesquisa. Acreditamos que para que se conheça a razão deste resultado seria necessária a realização de outras pesquisas, com questões que abordem pontos relacionados não apenas a formação que os alunos recebem em seus respectivos cursos, mas que abordasse pontos relacionados com suas vivências e também possíveis experiências profissionais.

\section{CONSIDERAÇÕES FINAIS}

Profissionais de diversas áreas do conhecimento têm se debruçado em estudar temáticas que abordem as fakes news na era da pós-verdade. Tanto os bibliotecários quanto os técnicos em Biblioteconomia, são mediadores da informação no cenário da bibliodiversidade, atuando veementemente na alimentação de bancos de dados, arquitetura da informação, gestão de portais de conteúdo e de acesso digital, bem como em outras atividades aliadas no combate à desinformação e à desordem informacional, que são pontos conflituosos nas relações entre as tecnologias e o comportamento humano nos dias de hoje. Através desse artigo e pelo cenário atual, consideramos que a temática das fake news, da desinformação e da pósverdade devem ser discutidas e evidenciadas por outras áreas do conhecimento, uma vez que adentram os territórios da ciência, da pesquisa e da inovação.

Através das análises realizadas, foi possível considerar que não exista uma dicotomia significativa entre as respostas obtidas pelos egressos do curso técnico em Biblioteconomia e dos alunos de graduação em Biblioteconomia na visão do assunto estudado pelos sujeitos da pesquisa. Julga-se importante destacar que um fator que deve ser levado em consideração 
seja a relação entre a fonte informacional ligada a veículos de comunicação formais e as fontes digitais ligadas às redes sociais. Nesse sentido, percebe-se que o suporte ainda acarreta um papel de fonte fidedigna segundo a visão dos entrevistados.

Tal levantamento demonstra que a relação de desconhecimento é muito significativa entre os alunos dos dois cursos, sendo um ponto importante a ser observado, a fim de realizar ações de ensino e de extensão relacionadas ao tema fake news. Visando preparar os futuros profissionais da Biblioteconomia para lidar com o fenômeno das fake news, acredita-se ser necessário um aprofundamento na compreensão e realização de estudos acerca da AMI, oportunizando o desenvolvimento de habilidades e competências para o acesso, uso e produção da informação e das mídias para a cidadania.

Para desdobramentos deste estudo, prospectamos que atividades como esta sejam realizadas no âmbito do Ensino e da Extensão, uma vez que bibliotecários e técnicos em Biblioteconomia irão se deparar com esse caos informacional no cotidiano das bibliotecas. Acredita-se ainda, que é necessário a implantação de políticas públicas voltadas à AMI, com o intuito de formar cidadãos com competências adequadas para utilizarem mídias e provedores de informação de maneira apropriada, compreendendo e reconhecendo suas necessidades informacionais, localizando e acessando as informações relevantes e, sobretudo, avaliando com senso crítico a credibilidade e a finalidade das informações e dados obtidos em suas pesquisas, além de combaterem a desinformação na sociedade contemporânea. Conforme preconiza a UNESCO (2011), a biblioteca e o bibliotecário são peças fundamentais para aplicação da AMI, tanto no auxílio ao professor, quanto na perspectiva de sujeito educador.

Por fim, compreendemos que tal pesquisa se torna relevante para identificar as limitações dos futuros profissionais e pensar em mecanismos curriculares e operacionais que possam promover um aprofundamento da em relação às práticas infocomunicacionais a serem consideradas no contexto informacional contemporâneo.

Para trabalhos futuros, prospectamos um estudo aprofundado nas diretrizes curriculares dos cursos de graduação em Biblioteconomia e no catálogo nacional de Cursos Técnicos, a fim de verificar a inserção de temáticas acerca da competência informacional, information literacy, alfabetização midiática e informacional nos projetos pedagógicos dos cursos (PPC) e nos ementários das disciplinas. Tais correlações são importantes para que os currículos dos cursos contribuam com o desenvolvimento profissional e pessoal destes indivíduos.

\section{REFERÊNCIAS}

ALMEIDA, N. B. F.a; BAPTISTA, S. G. Breve histórico da Biblioteconomia brasileira: formação do profissional. in: CONGRESSO BRASILEIRO DE BIBLIOTECONOMIA, DOCUMENTAÇÃO E CIÊNCIA DA INFORMAÇÃO, 25.,2013, Florianópolis, Anais [...]. Florianópolis: Federação Brasileira de Biblioteconomia, 2013. Disponível em:

https://portal.febab.org.br/anais/article/viewFile/1508/1509. Acesso em: 3 nov. 2020.

BLATTMANN, U.. O que são fontes e recursos informacionais? BVABCl. Florianópolis, 2010.Disponível em: http://bib-ci.wikidot.com/o-que-sao-font-es-e-recursosinformacionais. Acesso em: 26 abr. 2020.

CAPURRO, R.; HJORLAND, B. The concept of information as we use in everyday. In: Annaul Reviews of information Science and Techology. Medford: Information To- 
day,2003. p. 343-411.Disponível em: http://bogliolo.eci.ufmg.br/downloads/CAPURRO.pdf. Acesso em: 20 abr. 2020.

CASTRO, C. A. História da Biblioteconomia Brasileira. Brasília: Thesaurus, 2000. 287 p.

CHESNEY, B.; CITRON, D.. Deep Fakes: A Looming Crisis for National Security, Democracy and Privacy? LAWFARE. Washington, 21 fev. 2018. Disponível em:

https://www.lawfareblog.com/deepfakes-looming-crisis-national-security-democracy-andprivacy. Acesso em 15 set. 2020.

CIRIBELI, J.P.; PAIVA, V.H.P. Redes e mídias sociais na internet: realidade e perspectivas de um mundo conectado. Mediação, Belo Horizonte, v.13, n.12, jan./jun., 2011. Disponível em: http://www.fumec.br/revistas/mediacao/article/view/509. Acesso em: 5 set. 2019.

DACK, S. Deep Fake, Fake News, and What Comes Next. The Henry M. Jackson School of International Studies. University of Washington: Washington, 20 mar. 2019. Disponível em: https://jsis.washington.edu/news/deep-fakes-fake-news-and-what-comes-next/. Acesso em 20 set. 2020.

D'ANCONA, M. Pós-verdade: a nova guerra contra os fatos em tempos de fake news. Barueri: Faro Editorail, 2018.

DIAS, M. M. K.; PIRES, D. Fontes de informação: um manual para cursos de graduação em Biblioteconomia e Ciência da Informação. São Carlos: EDUFSCAR, 2005 DUNKER, Christian. Subjetividade em Tempos de Pós-verdade. In: Ética e Pós-verdade. Porto Alegre: Dublinense, 2017, p.11-41.

ESTABEL, L. B.; MORO, E. L. da S. Educação profissional e tecnológica em EAD: técnico em biblioteconomia do IFRS-Câmpus Porto Alegre. in: CONGRESSO BRASILEIRO DE BIBLIOTECONOMIA, DOCUMENTAÇÃO E CIÊNCIA DA INFORMAÇÃO, 26., 2015, São Paulo, Anais [...]. São Paulo: Federação Brasileira de Biblioteconomia, 2015. Disponível em:

http://repositorio.febab.org.br/items/show/1337. Acesso em: 3 nov. 2020.

FONSECA, B. O que é Fact-Cheking. Pública, São Paulo, 21 jun. 2017. Disponível em: https://apublica.org/2017/06/truco-o-que-e-fact-checking/. Acesso em 21 ago. 2020.

GARRETT, F. O que é Bot? Conheça os robôs que estão 'dominando' a internet. TECTUDO. Rio de Janeiro, 2018. Disponível em: https://www.techtudo.com.br/noticias/2018/07/o-que-ebot-conheca-os-robos-que-estao-dominando-a-internet.ghtml. Acesso em: 20 jun. 2020.

GUIMARÃES, A. de M. Internet. In: CAMPELLO, Bernadete; CALDEIRA, Paulo da Terra (Org.). Introdução às Fontes de Informação. 2 ed. Belo Horizonte: Autêntica Editora, 2008.

GRIZZLE, A.. Alfabetização Midiática e Informacional: diretrizes para a formulação de políticas e estratégias. Brasília: UNESCO, Cetic.br. 2016. 
INSTITUTO FEDERAL DO RIO GRANDE DO SUL [Organização: Lizandra Brasil Estabel, Angela Flach, Magali Lippert da Silva]. Projeto Pedagógico do Curso Técnico em Biblioteconomia, Porto Alegre, dez. 2010. Disponível em: http://www2.poa.ifrs.edu.br/wpcontent/uploads/2009/05/projeto_pedagogico_biblioteconomia.pdf. Acesso em: 15 nov. 2020.

IRETON, C.; POSETTI, J. Jornalismo, Fake News \& Desinformação. UNESCO, 2018.

MARCO DE AVALIAÇÃO GLOBAL DA ALFABETIZAÇÃO MIDIÁTICA E INFORMACIONAL (AMI): disposição e competências do país. Brasília: UNESCO, Cetic.br, 2016.

MOSTAFA, S. P.; TERRA, Marisa. Fontes eletrônicas de informação: novas formas de comunicação e de produção do conhecimento. São Paulo em perspectiva, São Paulo, v. 12 (4), out./dez. 1998. P. 54-59. Disponível em: http://produtos.seade.gov.br/produtos/spp/v12n04/v12n04_08.pdf. Acesso em: 23 nov. 2020.

MUELLER, L. P. M. O ensino de biblioteconomia no Brasil. Ci. Inf. Brasília, v.14, p.3-15, jan./jun. 1985. Disponível em: http://revista.ibict.br/ciinf/article/view/222/222. Acesso em: 3 nov. 2020.

RECUERO, R. Redes Sociais: na Internet. 2a .ed. Porto Alegre: Sulina,2011.

RIBEIRO, M. M.; ORTELLADO, P. O que são e como lidar com as notícias falsas. SUR 27, São Paulo, v.15, n.27, p.71-83, 2018. Disponível em: https://sur.conectas.org/o-que-sao-e-comolidar-com-as-noticias-falsas/. Acesso em: 16 set. 2019.

SANTOS, J. P.; SILVEIRA, I. M. F. da. Fabico, Fragmentos de uma Trajetória. Revista de Biblioteconomia \& Comunicação, Porto Alegre, v. 8, n. 1, p. 275-290, jan./dez. 2000. Disponível em: https://www.brapci.inf.br/index.php/res/v/99860. Acesso em: 30 out. 2020.

WANG, P.; ANGARITA, R.; RENNA, I. Is this the Era of Misinformation yet? Combining Social Bots and Fake News to Deceive the Masses. In WWW '18 Companion: The 2018 Web Conference Companion, April 23-27, 2018, Lyon, France. ACM, New York, NY, USA,.DOI: https: //doi.org/10.1145/3184558.3191610. Disponível em: https://www.researchgate.net/publication/323542704 Is this the Era of Misinformation $y$ et Combining Social Bots and Fake News to Deceive the Masses Acesso em: 15 nov. 2020.

WARDLE, C.; DERAKHSHAN, H.. Information Disorder: Toward na interdisciplinar framework for rearch and policy making. Concil of Europe, 2017. Disponível em: https://rm.coe.int/information-disorder-toward-an-interdisciplinary-framework-forresearc/168076277c. Acesso em: 4 jan. 2020.

WILSON, C. et. al. Alfabetização Midiática e Informacional: currículo para formação de professores. Brasília: UNESCO, UFTM, 2013. 


\section{ANEXO A}

Nome:

Idade:

Curso / Semestre:

1) Você se considera apto a identificar Fake News?

( ) SIM ( ) NÃO

2) Você já compartilhou algo nas redes sociais e depois descobriu que o conteúdo era falso?

( ) SIM ( ) NÃO

3) Na sua opinião, de quem é a responsabilidade pela verificação da veracidade de um conteúdo publicado?

( ) a responsabilidade é de quem compartilha

a notícia.

( ) as duas acima.

( ) a responsabilidade é de quem produziu a

( ) nenhuma das acima. notícia.

4) Quais as principais fontes de informação que você utiliza para se manter atualizado. Marque de 1 a 5, sendo 1 a mais importante e 5 a menos importante:
( ) Rádio
( ) Livros
( ) Jornais
( ) Revistas
( ) TV
( ) Whatsapp
( ) Sites de notícias
( ) Facebook
( ) Blogs
( ) Instagram
( ) Youtube
( ) Podcasts
( ) Twitter

5) Quais as principais fontes de informação que você utiliza para compartilhar notícias. Marque de 1 a 5, sendo 1 a que utiliza com mais frequencia e 5 a com menos:
( ) Sites de notícias
( ) Twitter
( ) Facebook
( ) Whatsapp
( ) Youtube
( ) Instagram
( ) Blogs
( ) Podcasts

6) Com relação às notícias compartilhadas:

( ) sempre compartilho sem checar a fonte.

( ) às vezes compartilho sem checar a fonte.

( ) nunca compartilho sem checar a fonte.

7) Dos termos abaixo coloque (S) de sim para os que você sabe o significado e (N) de não para os que você não sabe o que significa:
( ) Fact-checking
( ) Bots
( ) Fake News Científica
( ) Pós-Verdade
( ) Deep fake news
( ) Media and Information Literacy 